https://doi.org/10.48009/1_iis_2007_147-153

\title{
AN ONLINE LEARNING ENGINE FOR ETHICS EDUCATION: A PROOF OF CONCEPT USING BUSINESS ETHICS
}

\author{
Cecil Schmidt, Washburn University, cecil.schmidt@washburn.edu \\ Robert J. Boncella, Washburn University, bob.boncella@washburn.edu
}

\begin{abstract}
Learning to apply business ethics or ethics in general is difficult. Add to this the desire to have students learn ethics online and the task becomes more difficult. Most would agree that a major reason for the difficulty when using this approach, online education for ethics, is that seldom do the required subject matter expertise (SME) and technological and related pedagogical expertise (TPE), established on the basis of formal education and research expertise, reside in one person. The following is an attempt to create an online education engine based on Cognitive Flexibility Theory and the technology of Wikis. This online education engine is designed for the subject matter of ethics in general. We then give a proof of concept by instantiating it with the content of Business Ethics. When deployed, this learning engine will provide a standardized approach to learning to apply Business Ethics in context without the need for a stand alone Business Ethics course.
\end{abstract}

Keywords: Business Ethics, Cognitive Flexibility Theory, Learning Science

\section{INTRODUCTION}

The expertise for helping students learn ethics online seldom resides in a single person or resource. In particular instructors typically have domain expertise but need assistance from a specialist in the design of online course content. Furthermore, the generic ethics domain is a complex domain that contains sufficient formalism to basic content that lends itself to a rather structured learning approach. However, the illustration of the basic content and its application to specific cases is not easily acquired by a learner. As such, we look to the science of learning and the appropriate learning methodologies to guide us in the development of online content that best supports this domain.

Typical methodologies for learning such domains include the use of cases to illustrate the complexities of the associated problems. Students typically learn the content by reading and, or receiving lectures on the well structured content, reviewing case studies and how the theories apply on the complex content, and finally by constructing their own interpretations of case studies. Pedagogically, the students have to achieve outcomes using this methodology in a particular domain, i.e. content area. In general, for our research, the subject area domain is ethics, specifically the ethics in focus is Business Ethics. The set of outcomes to be achieved in this area using this method are listed below.

\section{BUSINESS ETHICS}

\section{Business Ethics as Applied Ethics}

Business ethics is concerned with what is right or wrong behavior in business situations. It is a normative field of ethics. As such, it is concerned with helping business persons answer the question: "What is ethical conduct in a particular business situation?"

There are three normative theories of business ethics [2]. These are: Shareholder Theory, Stakeholder Theory, and Social Contract Theory. Social Contract Theory is also referred to by the term "Corporate Social Responsibility." These theories are used to make a value based decisions on ethical problems related to business actions.

\section{Obstacles to Ethical Business Behavior}

There are two major obstacles to ethical decision making in business. First is the lack of "ethical sophistication" by the decision maker. And the second is that most often an ethical decision in a business situation is not an individual decision and as a result it is difficult to assign responsibility for that decision.

The first obstacle may be overcome if a number of different types of ethical issues and their resolutions can be provided to students who are learning about business ethics. And, in addition, provide students with an opportunity to resolve similar issues in academic environment.

The second obstacle is more difficult to overcome. The collective decision making in a business environment leads to the ambiguity of who is responsible for a decision. In an ethical situation this can inhibit an individual's ethical assertiveness. However, this inhibition can be reduced if an 
individual is confident in his/her applied ethical knowledge.

\section{LEARNER OUTCOMES}

Students need to acquire the skills to be able to make a value based decision on a social and ethical problems related to business actions. In order to do this students must demonstrate the following:

- Knowledge of different theories of ethical decision making so that they may be able to identify and to evaluate complex issues and logically defend their decisions.

- The ability to identify and distinguish among the various ethical theories related to business actions so that they may apply these appropriately in analyzing moral problems associated with business actions.

- The understanding that business knowledge is morally neutral but actions based on that knowledge may have moral consequences.

- The ability to identify and articulate the inadequacy of an ethical theory in a particular circumstance; that is, the ethical dilemmas that may arise when applying a particular ethical theory to a particular moral problem.

- The application of the ethical theories in the following business areas: finance and accounting, human resource management, sales and marketing, production, information systems, and international business.

These outcomes are achieved by students using a three step process. First, become acquainted with three prevailing business ethics theories (shareholder, stakeholder, and corporate social responsibility). Second, learn of possible moral problems within a business area (e.g. accounting or finance, or international business, etc.). Third, how that problem may be resolved using one of the three business ethics theories. Of these steps two and three are repeated often.

\section{ASSESSMENT OF OUTCOMES}

It is necessary to verify students have acquired the skills to analyze business situations requiring an ethical decision. One technique is to review the student analysis of a situation and see if certain metrics are used in the justification of action.

When the Shareholder Theory is used for justification two questions must be addressed. First, will this action maximize shareholder value? And second, can this action be taken without violation the firm's standards and without breaking the law?
When the Stakeholder Theory is used for justification two questions must be addressed. First, does the action maximize "collective" benefits to the firm? And second, does the action result in any of the corporate stakeholders being put at a disadvantage or being exploited?

When the Corporate Social Responsibility Theory is used for justification two questions must be addressed. First, does the action result in a benefit for society? And second, does the action result in any group being put at disadvantage or being exploited?

This formula of reviewing cases and then applying what a student has learned in analyzing new cases fits the constructivist model of learning. It is this model which is used to design and implement "A Learning Engine for Business Ethics” (LEBE).

\section{IMPLEMENTATION DESIGN}

\section{Framework}

The design of this LEBE is based on the framework of CBJava described in Schmidt [5], the generalized ethics course provided by Schmidt and Boncella in [6], and the hyper-book design used by the Engines for Education web site authored by Schank and Cleary [4]. In particular the design framework is a theory-based framework that applies the concepts set forth by the Cognitive Flexibility Theory as defined by Spiro, Feltovich, Jacobson, and Coulson [7] and the machine-based Case-based Reasoning (CBR) learning Cycle as defined by Aamodt \& Plaza[1].

Cognitive Flexibility Theory (CFT) is a constructivist learning theory that incorporates case-based learning as a significant part of its theory. As such, a casebased learning environment should incorporate features that support the five principles of CFT as identified by Spiro and Jacobson [3, 8]. These include: (1) use multiple conceptual representations of knowledge, (2) link and tailor abstract concepts to different case examples, (3) introduce domain complexity early, (4) stress interrelated and web-like nature of knowledge and (5) encourage knowledge assembly.

The Case-based Reasoning (CBR) Learning Cycle described in [1] identifies four processes that need to take place when implementing a CBR machine intelligent solution: (1) retrieve the most similar case or cases, (2) reuse the information and knowledge in that case to solve the problem, (3) revise the proposed solution, and (4) retain the parts of the experience likely to be useful for future problem solving. LEBE leverages both CFT and CBR within its framework. 
The foundational architecture of LEBE is a question and answer interface that is implemented in a hypertext environment on a wiki-based platform that has access to a relational database containing artifacts collected as part of both knowledge acquisition and user feedback. The wiki-based platform is implemented using PmWiki (www.pmwiki.org) and is accessible at www.ci4l.com. The design framework of LEBE includes the data architecture, user interface architecture, and knowledge acquisition architecture. These frameworks are addressed next.

\section{Data Architecture}

LEBE's data architecture consists of three conceptually related entities which provide the indexes into a case-base of related examples currently supporting a set database queries. The following is a list of the entities as well a brief description of each:

1. Content Area: this is a specific content area within business ethics such as finance and accounting, human resource management, or international business.

2. Ethical Theory: this is a particular ethical theory typically applied to business ethics such as shareholder, stakeholder, or corporate social responsibility theory.

3. Moral Problem: this is a specific area to which business ethics apply such as fair trade, child labor, or outsourcing.

4. Example: this is an example that has been submitted and catalogued that is related to a specific combination of content area, ethical theory, and moral problem. The example is typically a case study along with its resolution.

Current implementation of the database queries is primarily static. Dynamic queries are currently handled through the search engine contained as a component of the PmWiki implementation. Static queries are contained on the wiki content pages. These queries provide a cognitively flexible path through the content. The following is a list of the static queries and a description of each.

1. Give me some examples of the <moral problem $>$ in the <content area> and how they were resolved with <ethical theory $>$. Provides a set of links to cases that are related to a particular moral problem (e.g. creative accounting) within a content area (e.g. ethics of finance and accounting) and how they were resolved using a particular ethical theory (e.g. shareholder theory). Each link provides a path to the example.
2. Tell me how you would resolve the ethics of $<$ content area $>$ regarding <moral problem $>$ using <ethical theory>. Provides a link to an area where students are provided with a case study and students are asked to provide analysis of the moral problem in the content area, thus using a constructivist approach to learning. The analysis includes an application of a particular ethical theory.

3. How do I apply other <ethical theory> to $<$ moral problem $>$ in the area of $<$ content area $>$ ? Provides a set of links to the wiki-content of other ethical theories related to the content area. For example, if learners are viewing the stakeholder wiki-content for the moral problem of creative accounting within the content area of ethics of finance and accounting then links to the shareholder, and corporate responsibility ethical theories are provided that are related to the same content area and moral problem. Providing views of alternate ethical theories provides the CFT support necessary for learners to discern the differences and uniqueness of each.

4. How do I apply <ethical theory> to other $<$ moral problems $>$ related to <content area $>$ ? Provides a set of links to the other moral problems that are typical of the content area domain where the particular ethical theory has been applied. For example, if learners are currently viewing the wiki-content for the moral problem creative accounting where shareholder theory is being applied in the finance and accounting content area, then the links on the application of shareholder to all of the other moral problems are displayed. It is through the repetitive viewing of the theory over many different moral problem areas that enhances the learning for students.

5. How does this <content area $>$ relate to other $<$ content areas $>$ ? Provides links to the other Business Ethics content areas.

The primary implementation and storage of the user interface content is within a MySQL database whose content is primarily driven through an implementation of PmWiki. Additionally all examples are stored within the wiki which leverages the search capabilities that are already supported through the PmWiki installation.

\section{User Interface Architecture}

LEBE's hypertext user interface provides browserbased access through the World Wide Web to the instructional content as well as a case-based library. It supports a question and answer model through the 
clicking of links that act on the content. Entry into the content is initially provided through a matrix oriented display. See Figure 1. The matrix oriented display provides a point for learners to, at any time, re-center their context.

\section{<insert Figure 1 here>}

Clicking on a particular moral problem link takes users to the wiki-content for that moral problem, content area, and ethical theory. Once learners enter this wiki-content, they can review the content including resolved cases and also submit their own analysis of a case study. Additionally, learners can also pose other questions while within this content page. As an example, suppose a learner wished to pose a question about the application of Shareholder Theory towards the moral problem of Creative Accounting within the content area of the Ethics of Finance and Accounting. In that case the learner would click on the question "Tell me about how to apply Shareholder Theory to Creative Accounting!”. The system responds with an answer by displaying the web page on the Ethics of Finance and Accounting - Creative Accounting and the Application of Shareholder Theory (see Figure 2 and Figure 3). The response page provides links to the content area, the moral problem, and an overview of the ethical theory.

\section{<insert Figure 2 here> <insert Figure 3 here $>$}

\section{Knowledge Acquisition Architecture}

LEBE provides for the ability of learners to add content to the site. This an important feature of the system which lends itself to a CBR framework. Search capabilities of LEBE are managed through the initial indexing of cases by a learner and the revision and classifications by an expert. Cases are classified by the expert as part of the repair and revision with one of the following three classifications: (1) well defined, (2) adequate, or (3) needs work. Implementation of the search function across cases is currently handled through PmWiki.

LEBE's primary knowledge acquisition process involves the submission of case study analysis by learners. These cases are initially indexed based upon the wiki page that was used to perform entry. Further indexing of the example is performed by an expert. If the case analysis is not sufficient, then the expert makes the determination if the case can be repaired. If it is reparable, the expert makes the repair, saving both the case that was initially submitted, its original classification, and the repaired case.

\section{SUMMARY}

Learning to apply business ethics is difficult. The concept of how to apply and resolve these moral problems is complex and not easily learned. This domain complexity suggests that we exploit CFT as a guide in the development of instructional content. As such, we have developed a CFT-based prototype of a learning engine for business ethics (LEBE). When deployed, this learning engine will provide a standardized approach to learning to apply Business Ethics in context grounded by learning theory. Additionally, its web-base content and structure allow us to use the content either within a standalone Business Ethics course or independent of a standalone course. Finally, LEBE has a set of learner outcomes and the assessment of those outcomes associated with the engine.

The current state of the prototype is such that it is fully functional syntactically but semantically it is in need of more content. Over the next few months sufficient content will be added so that the LEBE can be tested. It is the intent of the researchers that this LEBE will become a learning resource in an academic unit.

\section{REFERENCES}

1. Aamodt, A., \& Plaza, E. (1994), Case-based reasoning: foundational issues, methodological variations, and system approaches." $A I$ Communications, 7(1), 39-59.

2. Cross, F.B., \& Miller, R.L. West's Legal Environment of Business: Text, Cases, Ethical, Regulatory, International, and E-Commerce Issues, $4^{\text {th }}$ ed., West - Thompson Learning, Cincinnati,OH, 2001.

3. Jacobson, M. J., \& Spiro, R. J., Hypertext learning environments, cognitive flexibility, and the transfer of complex knowledge: An empirical investigation. Journal of Educational Computing Research, 12 (4), 301-333, 1995.

4. Schank, R. C., \& Cleary, C., Engines for Education, 1995 , http://www.engines4ed.org/hyperbook/, Retrieved June 10, 2004.

5. Schmidt, C., Towards the support of cognitive flexibility in hypertext design, Journal of Computing Sciences in Colleges, Vol. 21, Number 4, April 2006. 
6. Schmidt, C. and Boncella, R. J., A framework for an ethics course for the information technology student, Issues in Information Systems, Vol VII, No. 1-2, 2006.

7. Spiro, R. J., Coulson, R. L., Feltovich, P. J., \& Anderson, D. K. (1988). Cognitive flexibility theory: Advanced knowledge acquisition in illstructured domains. (Technical Report No. 441). Champaign, Illinois: University of Illinois at Urbana-Champaign.
8. Spiro, R. J., Feltovich, R. P., Jacobson, M. J., \& Coulson, R. L. (1992). Cognitive flexibility, constructivism, and hypertext: Random access instruction for advanced knowledge acquisition in ill-structured domains. In T. M. Duffy, \& D. H. Jonassen (Eds.), Constructivism and the technology of instruction: A conversation (pp. 57-76). Hillsdale, NJ: Erlbaum.

\section{TABLES AND FIGURES}

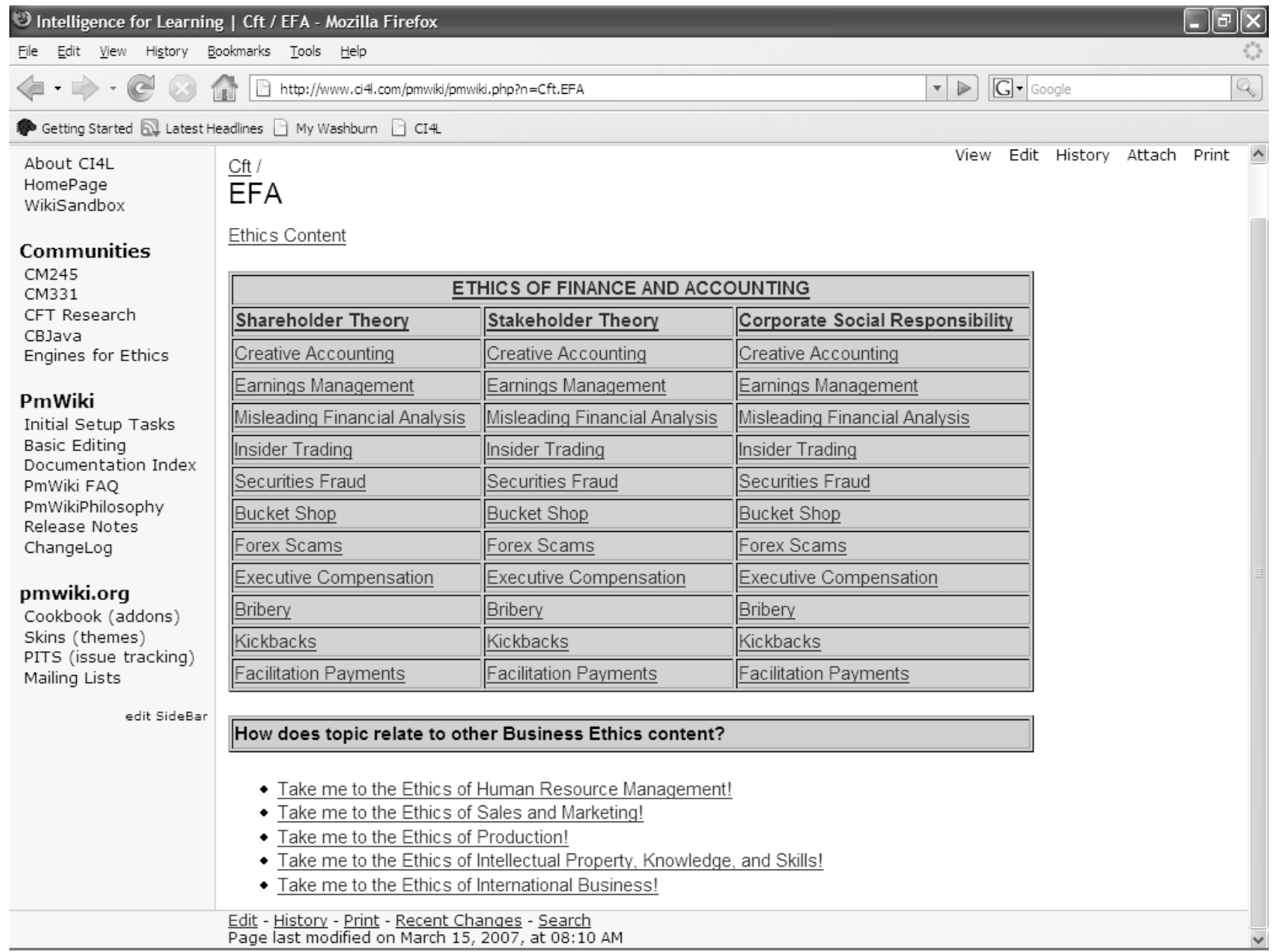

Figure 1. Entry page to the Ethics of Finance and Accounting content area. 


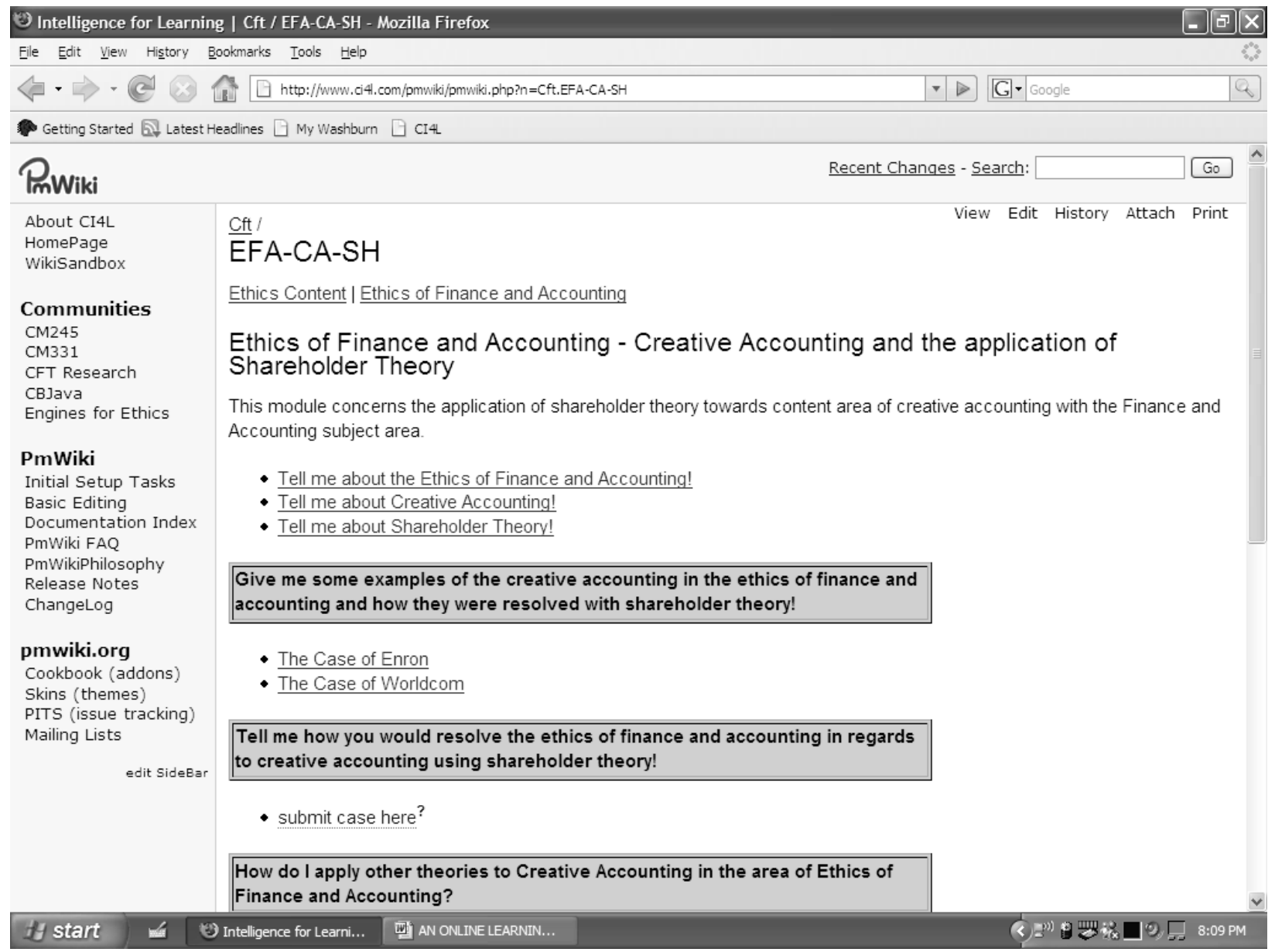

Figure 2. Part 1 of content page for the application of shareholder theory towards creative accounting. 


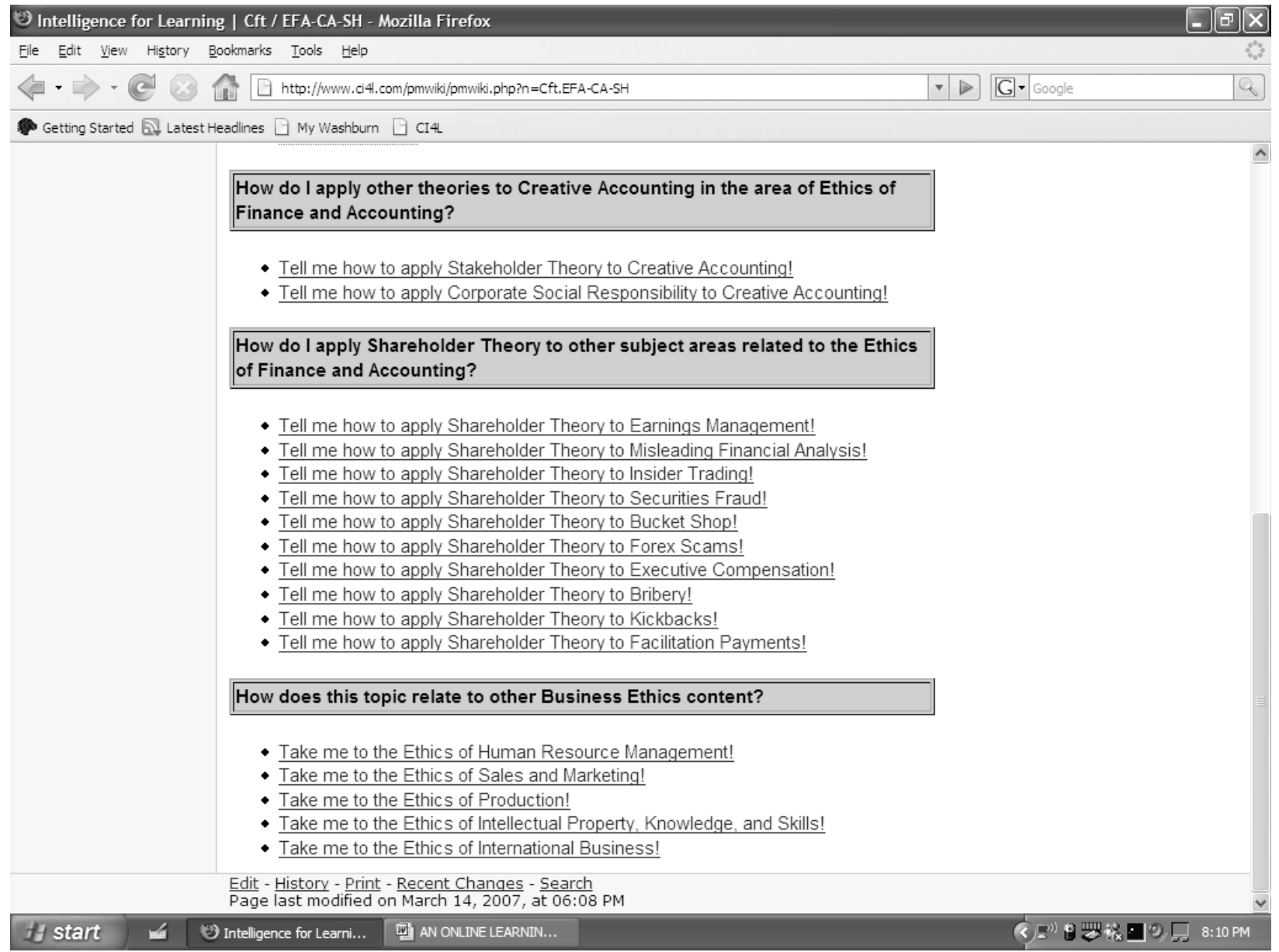

Figure 3. Part 2 of content page for the application of shareholder theory towards creative accounting. 